\title{
Clinico-Pathological study of carcinoma breast in a tertiary care hospital from West Bengal, India: A Cross-Sectional Observational study
}

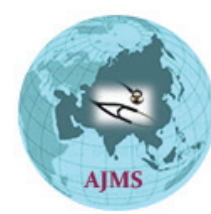

\author{
Deepak Kumar Sahoo', Mintu Mohan Nandi², Srijan Basu ${ }^{3}$, Sanjay Chatterjee ${ }^{4}$, \\ Amit Kumar Das ${ }^{5}$ \\ ${ }^{1}$ Junior Resident, ${ }^{2}$ Associate Professor, ${ }^{4}$ Senior Medical Officer, ${ }^{5}$ Assistant Professor, Department of Surgery, Deben \\ Mahato Govt. Medical College, Purulia, West Bengal, India, ${ }^{3}$ Senior Resident, Department of Surgery, Calcutta \\ National Medical College, Kolkata, West Bengal, India
}

\section{A B S T R A C T}

\begin{abstract}
Background: Breast cancer is one of the most common cancer in women. BC represents a heterogeneous group of tumors that are diverse in behavior, outcome, and response to therapy. Aims and Objective: The present study was undertaken to assess various clinical parameters and to evaluate correlation with histo-pathological grading in breast carcinoma patients. Materials and Methods: The study was conducted in the Surgical outpatient department and Indoor surgical wards of Deben Mahato Sadar Hospital (DMSH), Purulia, West Bengal from July, 2019 to December, 2020. 104 patients with diagnosis of BC aged between 20 years to 80 years were selected. Results: Among 104 patients, $41.3 \%$ patients were in the group of 41-50years. This study revealed that the patient had mostly IDC i.e. $78.8 \%$ and had triple negative BC (51.9\%). Association of HPE vs. Stage, subtypes vs stage and Tru-cut biopsy vs HPE were statistically significant. Conclusion: The study showed that breast cancer tends to present in middle aged women and positively correlate with the present markers of bad prognosis.
\end{abstract}

Key words: Breast Cancer (BC); Tru-cut Biopsy; Histopathological Examination (HPE)

\section{Access this article online}

Website:

http://nepjol.info/index.php/AJMS DOI: 10.3126/ajms.v12i9.36997 E-ISSN: 2091-0576

P-ISSN: 2467-9100

Copyright (c) 2021 Asian Journal of Medical Sciences

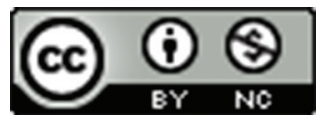

This work is licensed under a Creative Commons Attribution-NonCommercial 4.0 International License.

\section{INTRODUCTION}

Breast cancer is one of the most common cancers in women, worldwide and accounting for $25 \%$ of women with cancer, which are diagnosed every year throughout the world. Breast cancer is also listed as second leading cause of cancer related to death among women in the world. ${ }^{1,2}$ Breast cancer is also regarded as the most common cancer in women in many metropolitan cities, such as New Delhi, Mumbai, Ahmadabad, Kolkata, Trivandrum and the second most common cancer in the rest parts of the country. ${ }^{3,4,5}$ So screening and early diagnosis of the disease can lead to a good prognosis and a high survival rate. Mammography is a widely used screening approach in the detecting of breast cancer and proved to help reduce the mortality effectively. Other screening methods, such as Magnetic Resonance Imaging (MRI), which is more sensitive than mammography, have also been implemented and studied during the last decade. BC represents a heterogeneous group of tumors that are diverse in behavior, outcome, and response to therapy. The prognosis and treatment of the disease depends on various parameters such as the tumor size, lymph node status, histopathology, grade, stage and immuno-histochemistry status. Over the past decade, gene expression profiling and their correlation to immuno-histochemical markers have led to the identification of different molecular subtypes of breast cancer: 1) Luminal A 2) Luminal B 3) HER2 Positive 4) Basal-like. The present study was undertaken to assess 
various clinical parameters and to evaluate correlation with histo-pathological grading in breast carcinoma patients.

Aims and objective

1) To describe the mode of presentation of breast carcinoma.

2) To find out the ultrasonographic features of breast carcinoma among participants.

3) To correlate clinical findings, tru-cut biopsy and postoperative histopathology reports.

4) To determine Positive Predictive Value of trucut biopsy report with respect to Post operative histopathology report.

\section{MATERIALS AND METHODS}

The study was conducted in the surgical outpatient department and Indoor surgical wards of Deben Mahato Sadar Hospital (DMSH), Purulia, West Bengal from July, 2019 to December, 2020. All the patients with diagnosis of $\mathrm{BC}$ aged between 20 years to 80 years were included in the study. Pregnant, Lactating women with BC, All inoperable advanced breast malignancies, Multifocal/Multicentric BC, Previous radiotherapy in $\mathrm{BC}$, Previous breast surgery on same side breast cancer were excluded from the study. The study was an observational prospective study, where total one hundred and four cases were selected. Inferential statistics e.g. unpaired-' $t$ '-test, chi-squared test, odds ratio $(\mathrm{OR})$ with its $95 \%$ confidence interval (CI) etc. were used to establish the relation between input and output variables. $\mathrm{P}$ value of $<0.05$ will be considered as statistically significant.

\section{RESULT}

Among 104 patients, 43(41.3\%) patients were in the age group of 41-50years. Only 5(4.8\%) patient were in the age group of 71-80years old (Table 1).

We observed in our study that $49(47.1 \%)$ patients had menarche at 11-13years and $80(76.9 \%)$ patients were married. Sixty $(57.7 \%)$ patients had Menopausal status and maximum patient i.e. $63(78.8 \%)$ patients had a history of breast feeding. Maximum patients i.e. 36(45.0\%) patients had parity 1 . Only $8(7.7 \%)$ patients had family history of BC and 15(14.4\%) patients presented with obesity (Table 2).

Among 104 patients, 60(57.7\%) patients had lump and $81(77.9 \%)$ patients had pain. 19(18.3\%) patients presented with ulceration and $15(14.4 \%)$ patients presented with nipple discharge. 68(65.4\%) patients had tumor location at UO. Among 104 patients $99(95.2 \%)$ patients had malignancy on USG. After True cut biopsy, only 6(5.8\%) patients had atypical hyperplasia (Table 3).

\begin{tabular}{lcc}
\multicolumn{3}{l}{ Table 1: Age Distribution among patients } \\
\hline Age in Years & Frequency & Percent \\
\hline $21-30$ & 8 & $7.7 \%$ \\
$31-40$ & 25 & $24.0 \%$ \\
$41-50$ & 43 & $41.3 \%$ \\
$51-60$ & 8 & $7.7 \%$ \\
$61-70$ & 15 & $14.4 \%$ \\
$71-80$ & 5 & $4.8 \%$ \\
Total & 104 & $100.0 \%$ \\
\hline
\end{tabular}

\begin{tabular}{llcc}
\multicolumn{3}{l}{ Table 2: Risk Factors among patients } \\
\hline Parameters & & Frequency & Percentage \\
\hline Marital & Married & 80 & 76.9 \\
Status & Unmarried & 24 & 23.1 \\
Family & No & 96 & 92.3 \\
History & Yes & 8 & 7.7 \\
Menopausal & No & 44 & 42.3 \\
Status & Yes & 60 & 57.7 \\
Age at & <11 years & 16 & 15.4 \\
Menarche & $11-13$ years & 49 & 47.1 \\
& $>13$ years & 39 & 37.5 \\
BMI & Normal & 49 & 47.1 \\
& Over weight & 40 & 38.5 \\
& Obese & 15 & 14.4 \\
Breast & No & 17 & 21.3 \\
Feeding & Yes & 63 & 78.8 \\
Parity & 1 & 36 & 45 \\
& 2 & 26 & 32.5 \\
& 3 & 8 & 10 \\
& $\geq 4$ & 10 & 12.5 \\
\hline
\end{tabular}

After HPE report we observed that 82(78.8\%) patients had IDC and only $3(2.9 \%)$ patients had MC. Maximum patient i.e.59(56.7\%) patients had Stage 3. 56(53.8\%) patients had tumor size 2 to $4.9 \mathrm{~cm}$ and $44(42.3 \%)$ patients had $\geq 5$. $34(32.7 \%)$ patients had nodal status $>9$. Maximum patient i.e. $72(69.2 \%)$ patients had stage III and $87(83.7 \%)$ patients had NPI $\geq 5.9(8.7 \%)$ patients were positive HER2nue and $54 \%$ patients were TNBC (Table 4).

Association of HPE vs. Stage was statistically significant $(\mathrm{p}<0.0001)$. Association of Subtypes vs. Stage was statistically significant $(\mathrm{p}=0.0243)$ (Table 5 ).

Association of Tru-cut biopsy vs HPE was statistically significant $(\mathrm{p}<0.0001)$ (Table 6$)$.

\section{DISCUSSION}

In our study, we have found, 25(24.0\%) patients were in the age group of $31-40$ years old and $43(41.3 \%)$ patients were in the age group of41-50years. This present study also showed that 49(47.1\%) patient had menarche at 11-13years old. Some other study found that breast cancer with an average age at diagnosis of 59.4 years. ${ }^{6}$ Another study showed that age range was 18 to 82 years, with a mean of 45.17 years. ${ }^{7}$ This study showed that maximum patients i.e. 80 (76.9\%) 


\begin{tabular}{|c|c|c|c|}
\hline \multicolumn{2}{|c|}{ Clinical Parameters } & \multirow{2}{*}{$\begin{array}{c}\text { Frequency } \\
44\end{array}$} & \multirow{2}{*}{$\begin{array}{c}\text { Percentage } \\
42.3\end{array}$} \\
\hline Lump & No & & \\
\hline & Yes & 60 & 57.7 \\
\hline \multirow[t]{2}{*}{ Pain } & No & 23 & 22.1 \\
\hline & Yes & 81 & 77.9 \\
\hline \multirow[t]{2}{*}{ Ulceration } & No & 85 & 81.7 \\
\hline & Yes & 19 & 18.3 \\
\hline Nipple & No & 89 & 85.6 \\
\hline Discharge & Yes & 15 & 14.4 \\
\hline Quadrant & $\mathrm{C}$ & 14 & 13.5 \\
\hline \multirow[t]{3}{*}{ Involvement } & LO & 12 & 11.5 \\
\hline & UI & 10 & 9.6 \\
\hline & UO & 68 & 65.4 \\
\hline \multirow[t]{2}{*}{ USG } & Benign & 5 & 21.3 \\
\hline & Malignant & 99 & 78.8 \\
\hline Tru-cut & Atypical & 6 & 5.8 \\
\hline \multirow[t]{5}{*}{ Biopsy } & Hyperplasia & 4 & 3.8 \\
\hline & DCIS & 89 & 85.6 \\
\hline & IDC & 2 & 1.9 \\
\hline & LC & 3 & 2.9 \\
\hline & MC & & \\
\hline
\end{tabular}

\begin{tabular}{|c|c|c|c|}
\hline \multicolumn{2}{|c|}{$\begin{array}{l}\text { Clinico-pathological } \\
\text { Parameters }\end{array}$} & \multirow{2}{*}{$\begin{array}{c}\begin{array}{c}\text { Number of } \\
\text { Patient }\end{array} \\
9\end{array}$} & \multirow{2}{*}{$\begin{array}{c}\text { Percentage } \\
8.7\end{array}$} \\
\hline Subtypes & HER Positive & & \\
\hline & Luminal A & 23 & 22.1 \\
\hline & Luminal B & 18 & 17.3 \\
\hline & Triple Negative & 54 & 51.9 \\
\hline \multirow[t]{4}{*}{ HPE } & DCIS & 5 & 4.8 \\
\hline & IDC & 82 & 78.8 \\
\hline & LC & 14 & 13.5 \\
\hline & MC & 3 & 2.9 \\
\hline \multirow[t]{4}{*}{ Stage } & I & 7 & 6.7 \\
\hline & II & 20 & 19.2 \\
\hline & III & 59 & 56.7 \\
\hline & IV & 18 & 17.3 \\
\hline Tumor & $<2 \mathrm{~cm}$ & 4 & 3.8 \\
\hline \multirow[t]{2}{*}{ Size } & $2-4.99 \mathrm{~cm}$ & 56 & 53.8 \\
\hline & $\geq 5.00$ & 44 & 42.3 \\
\hline Nodal & 0 & 8 & 7.7 \\
\hline \multirow{3}{*}{ Status } & $1-3$ & 16 & 15.4 \\
\hline & $4-9$ & 46 & 44.2 \\
\hline & $>9$ & 34 & 32.7 \\
\hline \multirow[t]{3}{*}{ Grade } & 1 & 8 & 7.7 \\
\hline & 2 & 24 & 23.1 \\
\hline & 3 & 72 & 69.2 \\
\hline \multirow[t]{2}{*}{ NPI } & $\leq 5.4$ & 87 & 83.7 \\
\hline & $>5.4$ & 17 & 16.3 \\
\hline
\end{tabular}

were married. Also we have seen in our study that $60(57.7 \%)$ patient presented with breast lump and $81(77.9 \%)$ patients had pain. This study also revealed that $19(18.3 \%)$ patients had ulceration at the time of presentation and 15(14.4\%) patients had Nipple discharge. According to some other study, most patients presented with breast lump. ${ }^{8} \mathrm{Few}$ other study also supported this fact and the lump was associated with nipple discharge and ulceration.? The presenting complaints were a pain followed by pain with lump was also found by some study. ${ }^{10}$ We have seen in our study
Table 5: Association between HPE vs Stage and Subtypes vs stage

\begin{tabular}{llcccc}
\hline \multicolumn{1}{l}{ Parameters } & & Stage I & Stage II & Stage III & Stage IV \\
\hline \multirow{4}{*}{ HPE } & DCIS & $4(57.1)$ & $1(5)$ & $0(0)$ & $0(0)$ \\
& (Col\%) & & & & \\
& IDC (Col\%) & $2(28.6)$ & $9(45)$ & $53(89.8)$ & $18(100)$ \\
\multirow{5}{*}{ Subtypes } & LC (Col\%) & $1(14.3)$ & $10(50)$ & $3(5.1)$ & $0(0)$ \\
& MC (Col\%) & $0(0)$ & $0(0)$ & $3(5.1)$ & $0(0)$ \\
& HER 2 & $1(14.3)$ & $3(15)$ & $5(8.5)$ & $0(0)$ \\
& neu(Col\%) & & & & \\
& Luminal A & $4(57.1)$ & $4(20)$ & $7(11.9)$ & $8(44.4)$ \\
& (Col\%) & & & & \\
& Luminal B & $1(14.3)$ & $4(20)$ & $9(15.3)$ & $4(22.2)$ \\
& (Col\%) & & & & \\
& TNBC & $1(14.3)$ & $9(45)$ & $38(64.4)$ & $6(33.3)$ \\
& (Col\%) & & & & \\
\hline
\end{tabular}

$\begin{aligned} & \text { Table 6: Association between Tru-cut biopsy } \\
& \text { vs HPE }\end{aligned}$
\begin{tabular}{lccccc}
\hline Tru-cut Biopsy & \multicolumn{5}{c}{ HPE } \\
\cline { 2 - 6 } & DCIS & IDC & LC & MC & TOTAL \\
\hline Atypical & $2(33.3)$ & $2(33.3)$ & $2(33.3)$ & $0(0.0)$ & $6(100)$ \\
Hyperplasia & & & & & \\
(Row \%) & & & & & \\
DCIS (Row \%) & $2(50)$ & $2(50)$ & $0(0.0)$ & $0(0.0)$ & $4(100)$ \\
IDC (Row \%) & $1(1.1)$ & $78(87.6)$ & $10(11.2)$ & $0(0.0)$ & $89(100)$ \\
LC (Row \%) & $0(0.0)$ & $0(0.0)$ & $2(100)$ & $0(0.0)$ & $2(100)$ \\
MC (Row \%) & $0(0.0)$ & $0(0.0)$ & $0(0.0)$ & $3(100)$ & $3(100)$ \\
Total (Row \%) & $5(4.8)$ & $82(78.8)$ & $14(13.5)$ & $3(2.9)$ & $104(100)$ \\
\hline
\end{tabular}

that maximum patients i.e. $68(65.4 \%)$ patient presented with upper outer quadrant tumor. In this study, we also observed that 60(57.7\%) patients were postmenopausal and $63(78.8 \%)$ patients were in the breast-feeding group. The study also revealed that maximum patient i.e. $36(45.0 \%)$ patients had parity 1 and $8(7.7 \%)$ patients had family H/O breast cancer. The study showed maximum patients had normal BMI i.e. 49(47.1\%). Some other study revealed that maximum participants were in the age group of 41-50 years and belonged to lower class with mean age at menarche of 13.3 years, maximum patients were in premenopausal and most of them had upper outer quadrant involvement. ${ }^{11}$

In this study, we observed 99(95.2\%) patients had USG suggestive of malignancy. The study showed that on tru-cut biopsy, 6(5.8\%) patients had atypical hyperplasia, 4(3.8\%) patients had DCIS, $89(85.6 \%)$ patients had IDC, $2(1.9 \%)$ patients had LC and 3(2.9\%) patients had MC.But we observed in this study that all the patient had carcinoma of which maximum patient had IDC i.e. 82(78.8\%) after HPE examination. Another study found that Tru-cut biopsy had a sensitivity of $95.1 \%$, specificity of $100 \%$, positive predictive value of $100 \%{ }^{12}$ IDC, NOS is the most common histological type of breast cancer according to some other study. ${ }^{8}$ We found in our study that maximum patient had higher stage of presentation i.e. 59(56.7\%) patients had stage III disease and $18(17.3 \%)$ patients had stage IV disease. The study 
showed that 56(53.8\%) patients had tumor size 2 to $4.9 \mathrm{~cm}$ and $44(42.3 \%)$ patients had tumor size $\geq 5 \mathrm{~cm}$. We found in our study that $46(44.2 \%)$ patients presented with 4 to 9 nodes and $34(32.7 \%)$ patients presented with $>9$ nodes. We also found that $72(69.2 \%)$ patients had grade-III and $87(83.7 \%)$ patients had $\geq 5.4$ NPI. The study showed maximum patient had triple negative breast cancer i.e. 54(51.9\%). Other study showed that size of the mass was more than $5 \mathrm{~cm}$ involving multiple quadrants of breast and with positive lymph nodes in most of the cases and histologically, grade 3 tumor is most prevalent in this population. ${ }^{8}$ TNBC accounts for approximately $15-20 \%$ of newly diagnosed breast tumors according to some other study. ${ }^{13,14}$ This study also revealed that association of HPE vs. Stage was statistically significant $(\mathrm{p}<0.0001)$ and association of Subtypes vs. Stage was statistically significant $(\mathrm{p}=0.0243)$. The study also showed that association of True cut biopsy vs HPE was statistically significant $(p<0.0001)$.

\section{CONCLUSION}

In our study we have shown, the clinico-pathological properties and mode of presentation of breast cancer in a district hospital of west Bengal, India. The study showed that breast cancer tends to present in middle aged women and positively correlate with the present markers of bad prognosis. Also we have seen that TNBC is more prevalent at this area as evident from this study. More research is needed targeted at this group of patients as it is emerging as a therapeutic challenge to breast surgeons and oncologists.

\section{ACKNOWLEDGEMENT}

The authors take this opportunity to thank Department of Radiology and Pathology for their whole hearted support for this study.

\section{REFERENCES}

1. Stewart BW and Wild CP. World Cancer Report 2014. Geneva, Switzerland: WHO Press; 2014.

2. WHO: Geneva, Switzerland. Breast cancer. http://www. who.int/ cancer/prevention/diagnosis-screening/breast-cancer/en/.

3. Mishra S, Sharma DC and Sharma P. Studies of biochemical parameters in breast cancer with and without metastasis. Indian Journal of Clinical Biochemistry. 2004; 19:71-75.

https://doi.org/10.1007/BF02872394

4. Chandra AB. Problems and prospects of cancer of the breast in India. J Indian Med Assoc. 1979; 72:43-45.

5. Chopra R. The Indian Scene. Journal of Clinical Oncology 2001; 19:S106-S111.

6. Smith DR, Caughran J, Kreinbrink JL, Parish GK, Silver SM, Breslin TM, et al. Clinical presentation of breast cancer: Age, stage, and treatment modalities in a contemporary cohort of Michigan women. Journal of Clinical Oncology. 2011; 29 (27_suppl):1.

https://doi.org/10.1200/jco.2011.29.27_suppl.1

7. Kemfang Ngowa JD, Yomi J, Kasia JM, Mawamba Y, Ekortarh AC and Vlastos $\mathrm{G}$. Breast cancer profile in a group of patients followed up at the radiation therapy unit of the Yaounde General Hospital, Cameroon. Obstetrics and gynecology international. 2011; 2011. https://doi.org/10.1155/2011/143506

8. Saha K, Raychaudhuri G and Chattopadhyay BK. Clinicopathological study of breast carcinoma: A prospective two-year study in a tertiary care hospital. Clinical Cancer Investigation Journal. 2013; 2(1):34.

https://doi.org/10.4103/2278-0513.110773

9. Singh SK, Pankaj D, Kumar R and Mustafa R. A clinicopathological study of malignant breast lump in a tertiary care hospital in Kosi region of Bihar, India. International Surgery Journal. 2016; 3(1):32-36.

https://doi.org/10.18203/2349-2902.isj20151216

10. Egwuonwu OA, Anyanwu SN, Chianakwana GU and Ihekwoaba EC. Breast Pain: Clinical pattern and aetiology in a breast clinic in Eastern Nigeria. Nigerian Journal of Surgery. 2016; 22(1):9-11. https://doi.org/10.4103/1117-6806.169822

11. Shoeb MF, Pinate AR and Shingade PP. Breast cancer, Clinical presentations, Risk factors, Staging. International Surgery Journal. 2017; 4(2):645-649. https://doi.org/10.18203/2349-2902.isj20170207

12. Rikabi A and Hussain S. Diagnostic usefulness of tru-cut biopsy in the diagnosis of breast lesions. Oman medical journal. 2013; 28(2): 125 .

https://doi.org/10.5001/omj.2013.32

13. Perou CM, Sorlie T, Eisen MB, van de Rijn M, Jeffrey SS, Rees CA, et al. Molecular portraits of human breast tumours. Nature. 2000; 406: 747-752.

https://doi.org/10.1038/35021093

14. Carey LA, Perou CM, Livasy CA, Dressler LG, Cowan D, Conway K, et al. Race, breast cancer subtypes, and survival in the carolina breast cancer study. JAMA. 2006: 295: 2492-2502. https://doi.org/10.1001/jama.295.21.2492

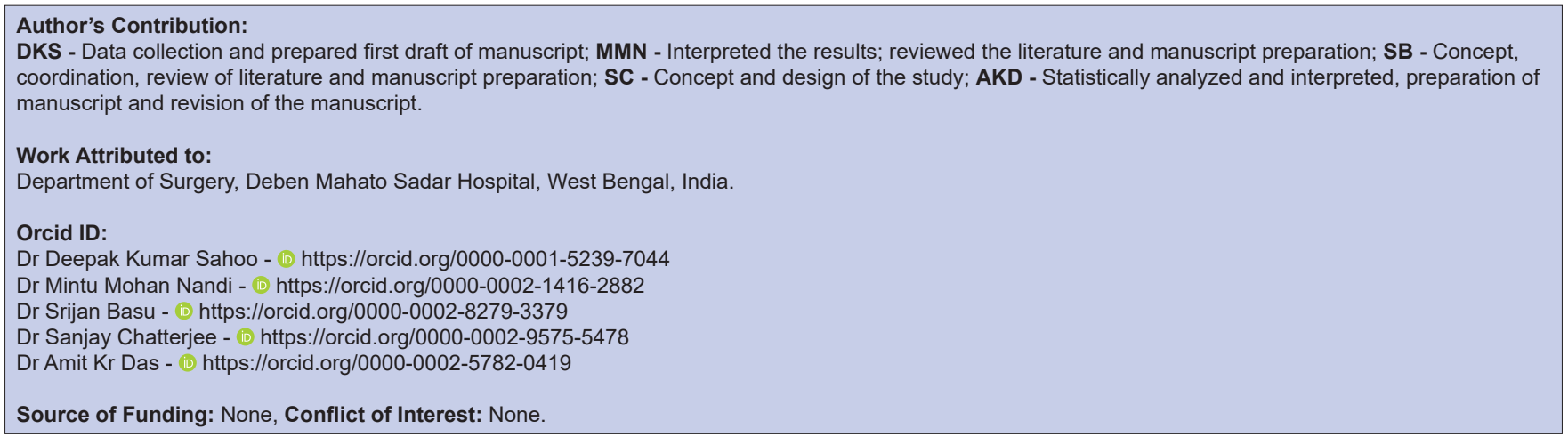

